\title{
Aligning human resources and business strategy
}

\author{
Mojtaba Kateb ${ }^{a}$ and Ali Akbar Ahmadi ${ }^{\text {* }}$
}

${ }^{a}$ Ph.D in Public Management, Department of Public Management, Payame Noor University, Tehran, Iran ${ }^{b}$ Professor Department of Public Management, Payamme Noor University, Tehran, Iran

CHRONICLE ABSTRACT

\begin{tabular}{l} 
Article history: \\
Received: July 9, 2018 \\
Received in revised format: July \\
9, 2018 \\
Accepted: September 4, 2018 \\
Available online: \\
September 4, 2018 \\
\hline Keywords: \\
Strategic Alignment \\
Fuzzy Logic \\
Delphi Technique \\
Business Strategy \\
Human Resources Strategy \\
Strategic Reference Point \\
\hline
\end{tabular}

This paper aims to provide a fuzzy framework for aligning human resources strategies with business strategies at The University of Applied Science and Technology. This research is an applied research based on the purpose and the research time horizon is cross sectional. In this research, 15 experts are identified using snowball method. The necessary data are gathered based on 3 questionnaires including Delphi questionnaire, human resources (HR) and business strategic questionnaire. The results show that some couples of HR strategies were aligned with business strategies. Then "if-then" rules are described in FuzzyTech software and the study determines which business strategies must be aligned with human resources strategies using the analysis. The paper ends by providing some suggestions based on 16 possible scenarios.

\section{Introduction}

University of Applied Science and Technology (UAST) plays an important role in higher education system of Iran because of its role in training practical education. The main purpose of this university is to provide a suitable context for students to work in public and private organizations. Providing this context needs some experts in the body of university as instructors and programmers. The university helps graduates acquire the necessary knowledge and skills for the future activities. This university has a special competitive advantage in the educational science space, and cleats a link between business, industry and university. The university combines science and its applications in an effort to reach the industries that have institutionalized knowledge through the use of practical science. But the problem here is that the strategies of the UAST, have not been well implemented. This issue can be originated from human resources as the most important element for implementing organizational strategies. Human resource is critical for the success of organizations and it seems that the main problem of UAST is the gap between business strategies and HR strategies (Saini, 2003). Many organizations solve this problem by hiring skilled employees but UAST does not presently have a compensation package to hire professionals. In this way, sense of trust, commitment and self-reliance are created among individuals, and the sense of

* Corresponding author.

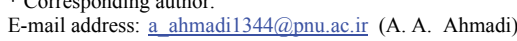

(C) 2018 by the authors; licensee Growing Science, Canada doi: $10.5267 /$ j.msl.2018.9.001 
participation in organizational affairs will increase and ultimately lead to performance improvement (Batarliene et al., 2017; Ulrich et al., 1995). If UAST wants to decrease its dependence to public budget, it has to focus on hiring fewer experts and this is in contrast with increasing the quality of education. The main problem is find how it is possible for UAST to align these strategies and which HR strategies are best aligned with business strategies? The primary objective of this paper is to develop a fuzzy based framework for strategic alignment.

\section{Literature review}

In this research, in order to identify the strategic reference points (SRP), the researchers first examined a variety of business and human resources. Among the studies, some strategic reference points were identified in business strategies. The strategic reference points include internal factors (weakness and strength), external factors (threats and opportunities), competition domains (limited and broad), competitive advantage (cost reduction and differentiation), environmental change (low and high), complexity of the environment (low and high), competitive situation (weak and strong), market attractiveness (low and high), product and service (existing and new) and market (existing and new). In addition, different models for classification of HR strategies were also investigated and strategic reference points of the focus (internal and external), the focus of control (outcome and process), and concentration (low and high), based on the environment (stability and flexibility) and the provision of resources (inside and outside) were identified (Divandari et al., 2014). Therefore, a set of strategic reference points were identified, each of which could be appropriate for assessing business and HR strategies (Gannon et al., 2015; Holbeche, 2009). The strategic reference points model were used to examine the alignment between human resources and business strategies and the main reason for choosing this model can be explained based on what is needed between the alignment of different organizational elements such as business strategy and human resource measures. The matrix of strategic reference points seems to be a framework that can be helpful (Arabi \& Moghaddam, 2007; Bird \& Beechler, 1995). Reference points are in fact a hypothetical criteria that are formed in the minds of the managers of the organization and they measure the position of their organization on this basis (Ou et al., 2009). The theory of strategic reference points suggests a combination of two rational and natural approaches that have been adopted between these two approaches and by defining a central criterion, the general priorities of the system are determined and embedded in a strategy, so that all stakeholders are guided according to the principles and principles. Feigenbaum (1999) defines strategic reference points as goals or criteria that managers use to assess their choices and determine organizational priorities for making strategic decisions and although the experts advised a three dimensional matrix (internal, external, and time); but due to the simplicity, the two-dimensional models, have become more prominent and it was used (Ahmadi et al., 2017).

Amin (2015) investigated the effect of alignment of business strategies and human resources on key performance indicators and found some positive impacts of various HR and business strategies on the key financial performance indicators and employee satisfaction. Abbasi et al. (2017) developed a model for human resource strategy coherent with business strategies, culture and organizational structure. He explained that business strategy followed conservative type, organizational structure followed mechanical type, organizational culture strategy follows mission type and ultimately the contractual human resources strategy followed contractual type. In order to formulate human resources strategies in line with business strategies, organizational structure and culture, scenarios were stated that the company could use. Linton and Kresk (2016) investigated the configuration of entrepreneurial orientation (EO) and competitive strategy for exalted performance in Swedish organizations. They explained how the dimensions of the EO in a nonlinear manner, when in line with competitive strategies, could facilitate company performance. Mahmoud Janlou (2017) investigated the strategy of human resources using the theory of strategic reference points. He reported that suitable strategy for managerial jobs could be considered as devotional strategy. 
Studies have shown that the strategic reference points approach has not been used to align business strategies with human resources strategies at universities and in this respect, we cannot be sure about the most appropriate points of reference. But what's important is the selection of the best strategic reference points using the experts of University of Applied Science and Technology. During the process of reviewing the documents related to human resources management measures at University of Applied Science and Technology and interviewing the experts of this university, the researchers achieved the fact that presently, this university has not developed specific processes and activities in various areas of human resources management, especially salary, education, maintenance and recruitment and in line with environmental changes and the conditions governing the organization, and with the change in their strategic position, these actions have not been markedly changed. This factor identifies the lack of a scientifically developed model for compiling human resources management practices appropriate to different strategic positions at University of Applied Science and Technology.

\section{Research methodology}

The present research is considered as an applied research because its results are used to facilitate the alignment of HR strategies with business strategies of university and seeks to resolve the problems and issues of aligning strategies that normally need to be solved in the long run. The method is also mixed because Delphi's qualitative method and fuzzy quantitative method are used to provide a coherent framework for alignment. It is also a case study. The experts' population of the research consists of 15 deputies, experts and senior advisors of the Central Organization of University of Applied Science and Technology in Tehran. In this population, purposive sampling is used which is in a desirable situation, due to dispersion, probabilistic sampling is inefficient and generalization is not essential to the whole society. To identify, snowballing method was used and its number was determined with respect to access. Table 1 shows the general particulars of experts.

Table 1

Descriptive statistics of the experts and specialists population

\begin{tabular}{ccccc}
\hline \multicolumn{2}{c}{ Gender } & \multicolumn{2}{c}{ Education } & Academic field of study \\
\hline Male & Female & Ph.D \& member of faculty member & $\begin{array}{c}\text { Public administration and } \\
\text { strategy }\end{array}$ & Other fields \\
\hline 11 & 4 & 15 & 6 & 6 \\
\hline
\end{tabular}

Data collection method was a questionnaire. Delphi questionnaire and fuzzy alignment questionnaire were submitted to the experts in several stages. Validity of the questionnaires was confirmed by professors and experts before distribution. The reliability of the Delphi questionnaire was also calculated through interviewing the experts. The method of analyzing the collected data is also a fuzzy Delphi method and a fuzzy analysis method. The Delphi method is one of the successful methods used to reach a consensus among a number of experts through a questionnaire on a specific topic. The Delphi method is a repetitive process for collecting unnamed expert judgments. The implementation phases of the fuzzy Delphi method are in fact a combination of the implementation of the Delphi method and analysis on information using the definitions of the theory of fuzzy sets, which are as follows:

1. Selecting experts and explaining the issue for them; 2. Preparing a questionnaire and sending it to experts; 3. Getting experts' opinion and analyzing them: At this stage, the questionnaire is sent to the members of the expert group and their agreement amount is taken with each of the components and the points of view and corrective points are summed up. According to the questions of the questionnaire and the linguistic variables defined in the questionnaire, the fuzzy mean of each of the components is calculated according to the following relations (Siahkali Moradi et al., 2017).

$$
\begin{aligned}
& A^{i}=\left(a_{1}^{(i)}, a_{2}^{(i)}, a_{3}^{(i)}, a_{4}^{(i)}\right), i=1,2,3, \ldots, n \\
& A_{\text {ave }}=\left(m_{1}, m_{2}, m_{3}, m_{4}\right)=\left(\frac{1}{n} \sum_{i=1}^{n} a_{1}^{(i)}, \frac{1}{n} \sum_{i=1}^{n} a_{2}^{(i)}, \frac{1}{n} \sum_{i=1}^{n} a_{3}^{(i)}, \frac{1}{n} \sum_{i=1}^{n} a_{4}^{(i)}\right) .
\end{aligned}
$$


In Eq. (1), $A^{i}$ represents the $\mathrm{i}^{\text {th }}$ expert's opinion and in Eq. (2), $A_{\text {ave }}$ represents the mean of the experts' opinions, which are represented in trapezoidal fuzzy number.

4. In this step, the previous point of view of each person and the degree of difference with the mean of the views of others along with the next round of questionnaires are again sent to the experts.

5. After conducting a new round of polls, according to the views presented in the first stage and comparing them with the new round results, if the difference between the two stages is less than the threshold of 0.2 , the polling process will be stopped. The threshold is calculated from the following equation:

$$
s\left(A_{m 2}, A_{m 1}\right)=\left|\frac{1}{4}\left[\left(a_{m 21}+a_{m 22}+a_{m 23}+a_{m 24}\right)-\left(a_{m 11}+a_{m 12}+a_{m 13}+a_{m 14}\right)\right]\right| .
$$

If the difference between the two steps is greater than the threshold, then we return to step 4 .

6. If the difference between the two steps is less than the threshold, the fuzzy Delphi process ends (Siahkali Moradi et al., 2017).

In the following, decision making in a fuzzy environment including three steps were used to align the strategies:

The first phase of the fuzzing the actual variables is based on experts' opinions. The second stage is the fuzzy inference in which, based on if-then rules, it determined which fuzzy decision-making period would lead to which result. The result of this inference is a linguistic value for the linguistic variable. The third step is the conclusion based on the linguistic values that the researcher identifies the outcomes and probabilities of different states using analyzes and deductions (Azar et al., 2011).

\section{Analysis}

\subsection{Fuzzy Delphi Technique}

In the following, the inspection steps in determining the strategic reference points are presented:

\subsubsection{Determining business strategy reference points}

\section{Definition of linguistic variables}

As noted, the questionnaire is intended to obtain experts' opinion about the selection of the most appropriate strategic reference points. Therefore, experts must express these values through variables. The use of variables with definite values makes it difficult for experts to comment. For this reason, it is clear that the qualitative variables give more freedom to the experts. The use of qualitative variables such as "low", "moderate", "high" will solve some problems to some extent. People's views are not the same for qualitative variables such as low or high. Since experts have different characteristics, they have different mindsets, and if the options are answered on the basis of different mindsets, the analysis of the variables is not worthwhile. But by defining the range of qualitative variables, experts with the same mindset will answer the questions. Therefore, qualitative variables are defined as fuzzy numbers of the same form (Karyotis et al., 2018): as "low" $(0,0,2,4)$, "moderate" $(3,4,6,7)$, "high" $(6,8,10,10)$. Trapezoidal fuzzy numbers given as (a, b, c, d), although having a more complex computing process than triangular fuzzy numbers, but can be in the range of $b$ to $c$, defined for trapezoidal fuzzy numbers, and carry more ambiguity in verbal and qualitative variables and while this interval in triangular numbers becomes a point ' $b$ '. According to the proposed options and the definition of linguistic variables, a questionnaire was designed. The results of inspecting the questionnaire responses are presented in Table 2. Based on the results, the mean of the indexes for the selection of the most suitable strategic reference points for business strategies is calculated according to the following relationships. At this stage, the experts were asked to choose the degree of suitability of each of the strategic reference points of the business strategy of University of Applied Science and Technology as a low, high, medium options. 
Table 2

Results from counting the answers of the first questionnaire

\begin{tabular}{lccc}
\hline Strategic Reference Points for Market Strategy & \multicolumn{2}{c}{ Suitability for university } \\
\hline Internal factors (weakness and strength) & Low & Moderate & High \\
\hline External factors (threats and opportunities) & 4 & 6 & 5 \\
Scope of competition (limited and extensive ) & 3 & 6 & 6 \\
Competitive Advantage (Cost Reduction and Differentiation) & 0 & 1 & 14 \\
Environment Change (low and high) & 0 & 0 & 15 \\
Complexity of environment (low and high) & 4 & 6 & 5 \\
Competitive position (weak and strong) & 3 & 2 & 10 \\
Market attractiveness (low and high) & 4 & 6 & 5 \\
Product and service (existing and new) & 3 & 6 & 6 \\
Market (existing and new) & 4 & 6 & 5 \\
\hline
\end{tabular}

We also converted the resulting fuzzy numbers into definite numbers through the Minkowski formula $\mu_{d f}(R)=\frac{a+2(b+c)+d}{6}$

\section{Table 3}

Average of experts' opinions

\begin{tabular}{lcc}
\hline Strategic Reference Points for Market Strategy & $\begin{array}{c}\text { Selecting the most suitable } \\
\text { reference points }\end{array}$ & Defuzzification mean \\
\hline Internal factors (weakness and strength) & {$[3.8,5.9,6.7,7.8]$} & 6.13 \\
External factors (threats and opportunities) & {$[4.8,5.1,7.1,7.8]$} & 6.17 \\
Scope of competition (limited and extensive ) & {$[5.8,7.8,9.7,9.8]$} & 8.43 \\
Competitive Advantage (Cost Reduction and Differentiation) & {$[6,8,10,10]$} & 8.67 \\
environment Change (low and high) & {$[3.8,5.9,6.7,7.8]$} & 6.13 \\
Complexity of environment (low and high) & {$[4.8,5.1,7.1,7.8]$} & 6.17 \\
Competitive position (weak and strong) & {$[4.8,6.4,8.4,8.8]$} & 7.20 \\
Market attractiveness (low and high) & {$[5.8,7.8,9.7,9.8]$} & 8.43 \\
Product and service (existing and new) & {$[4.8,5.1,7.1,7.8]$} & 6.17 \\
Market (existing and new) & {$[3.8,5.9,6.7,7.8]$} & 6.13 \\
\hline
\end{tabular}

According to Table 3, the divergence of views of each expert can be calculated according to Eq. (3). In fact, based on this equation, each expert can measure his/her opinion with respect to the mean score and modify his/her previous opinions if necessary. Using the Eq. (3), the experts' divergence of views were calculated and set in a questionnaire. Then, each of the experts announced new comments regarding their reassessment of their previous opinions. Similarly, the second and the third stages of the distribution of the questionnaire were carried out in order to reach the consensus of experts, and the following results were obtained:

\section{Table 4}

Results obtained from the second stage

\begin{tabular}{lccc}
\hline Strategic Reference Points for Market Strategy & divergence of views & Mean & Final opinion \\
\hline Internal factors (weakness and strength) & 0.55 & 5.53 & Next stage \\
External factors (threats and opportunities) & 0.7 & 5.53 & Next stage \\
Scope of competition (limited and extensive ) & 0.225 & 8.67 & Confirmation \\
Competitive Advantage (Cost Reduction and Differentiation) & 0 & 8.67 & Confirmation \\
Environment Change (low and high) & 0.25 & 5.83 & Elimination \\
Complexity of environment (low and high) & 0.7 & 0.7 & Next stage \\
Competitive position (weak and strong) & 1 & 1 & Next stage \\
Market attractiveness (low and high) & 2.775 & 2.775 & Next stage \\
Product and service (existing and new) & 0.4 & 0.4 & Elimination \\
Market (existing and new) & 0.25 & 0.25 & Elimination \\
\hline
\end{tabular}

According to the results of the disagreements, it is clear that the experts only agreed on the consensus opinion in only third and four items (difference less than 0.5 and mean higher than 6.5) and in the Fifth, Ninth and Tenth items, there has also been a consensus on elimination (difference less than 0.5 and mean 
less than 6.5). There are also divergence of views about other items (mean greater than 0.5 ). So the review of 5 items was postponed to the next. Thus, in the case of two items where consensus has been reached on the agreement, their Defuzzification mean should be more than 6.5 and the difference between the two stages should be less than 0.5 (Siahkali Moradi et al., 2017), and this condition holds only for the third and fourth indices. The remaining 5 strategic points were sent to the experts in the questionnaire to determine the experts' consensus. The results of the distribution and collection of the third stage questionnaires are presented in Table 5.

\section{Table 5}

Results obtained from the third stage

\begin{tabular}{lccc}
\hline Strategic Reference Points for Market Strategy & divergence of views & Mean & Final opinion \\
\hline Internal factors (weakness and strength) & 0.2 & 5.83 & Elimination \\
External factors (threats and opportunities) & 0 & 5.53 & Elimination \\
Scope of competition (limited and extensive ) & 0 & 5.53 & Elimination \\
Competitive Advantage (Cost Reduction and Differentiation) & 0.48 & 5.83 & Elimination \\
Environment Change (low and high) & 0 & 5.53 & Elimination \\
\hline
\end{tabular}

Given that the mean achieved for strategic reference points is less than 6.5 , it is clear that the consensus of experts is identified from the two strategic points in the first and the second stages and the experts prefer to on focus on the same two points that are:

Strategic Reference Point 1: Competition scope (Limited and Extensive), Strategic Reference Point 2: Competitive Advantage (focus on cost, focus on differentiation).

\subsubsection{Determination of human resources strategy reference points}

Given the suggested options and definition of linguistic variables, the questionnaire was designed to evaluate the opinions of experts around each strategic point in HR strategies. For this section, only the final results are presented. The method of determining the strategic reference points of human resources has also been similar to the strategic reference points of the business.

\subsection{Fuzzy alignment}

In order to identify aligned and unaligned strategies, experts were asked to identify the alignment and non-alignment of strategies on a 5-point scale in a similar questionnaire.

\section{Table 6}

Sample of Delphi Questionnaire for aligning strategies

\begin{tabular}{|c|c|c|c|c|}
\hline $\begin{array}{c}\text { HR strategies } \\
\text { Business } \\
\text { strategies } \\
\end{array}$ & $\begin{array}{l}\text { Controlling Outcome - Supply- } \\
\text { ing from inside (committed) }\end{array}$ & $\begin{array}{l}\text { Controlling Process - Sup- } \\
\text { plying from inside (parental) }\end{array}$ & $\begin{array}{l}\text { Controlling Result - Supplying } \\
\text { from outside (contractual) }\end{array}$ & $\begin{array}{l}\text { Controlling Process - Supply- } \\
\text { ing from outside (secondary) }\end{array}$ \\
\hline \multicolumn{5}{|l|}{ Cost - Focus } \\
\hline \multicolumn{5}{|l|}{$\begin{array}{l}\text { Cost }- \text { Sepa- } \\
\text { ration }\end{array}$} \\
\hline \multicolumn{5}{|l|}{$\begin{array}{l}\text { Distinction - } \\
\quad \text { Focus }\end{array}$} \\
\hline $\begin{array}{l}\text { Distinction - } \\
\text { Separation }\end{array}$ & & & & \\
\hline
\end{tabular}

The questionnaire was sent to the experts and their comments were collected. Then, fuzzy logic and fuzzy TECH 8.4 software were used to determine the alignment of business strategies with HR strategies. In a way that input of the software of two strategic reference points of human resources was namely control and supply and the software output was the alignment with two strategic business reference points, i.e. the advantage and scope of the competition. Finally, the model drafted in the study was designed as follows: 


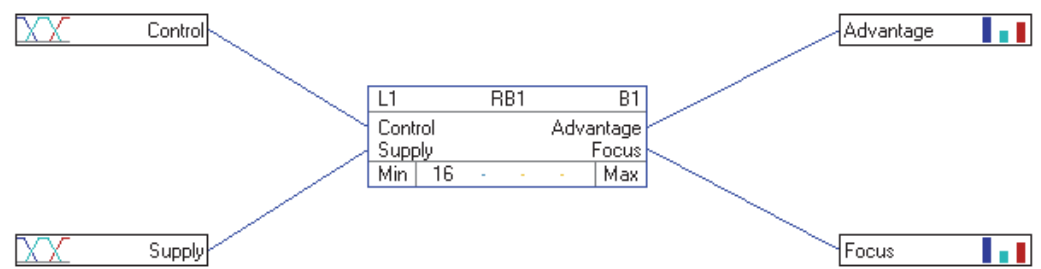

Fig. 2. Designed model in fuzzy TECH 8.4 software

\subsubsection{Designing Model Logic}

In order to consider the logic of the fuzzy model, we need to determine how the alignment is defined. Basics of alignment in strategies, the use of their main concepts means the need for cost, the need for variety of skills, simple and complex occupations and the type of control required and the manner of supply, according to the expertise and cost of their provision. Based on this, using the studied references and the logic in the strategies, the analysis of the basis of alignment was discussed.

\section{Cost-focus strategy}

According to this typology of organization competitive strategies and human resources strategies, companies that use cost-cutting strategies should be very careful about controlling and reducing costs and thus achieving higher economic scales. In this way, it can be briefly stated that Cost - Focus strategy needs to a low cost of human resources supply and focus on the process to reduce costs. On the other hand, it needs less variety of skills and expertise, so repetitive and less specialized occupations are considered in this area. That's why inside supply becomes more important.

\section{Table 8}

Basis of alignment in strategies based on low cost and high focus

\begin{tabular}{ccccc}
\hline Strategic reference points & Business strategy & & HR strategies & Strategic reference points \\
\hline Advantage & Less cost & As a result & Focus on process & Control \\
Scope & More focus & As a result & Supply from inside & Supply \\
\hline
\end{tabular}

In the case of business strategy, where the basis of the competitive advantage is the cost and the focused competitive area, we should focus on the processes and costs of doing things, as well as the available resources of the organization. In this way, the choice of human resources strategies should be based on this.

\section{Cost - Separation strategy}

When an organization tries to provide services with high expertise and complexity at low cost, it must use a cost-separation strategy that requires a low cost of human resources supply and focus on the outcome due to the variety of services and complexity and expertise. In this case, the competitive advantage is low cost, but the area of separation performance is high and the providing services is diverse, therefore, the organization must act on the supply of resources from the inside in order to control costs, but because of the high complexity of the services, it cannot monitor the whole process. So the focus is on the outcome.

\section{Table 9}

Basis of alignment in strategies based on low cost and high separation

\begin{tabular}{ccccc}
\hline Strategic reference points & Business strategy & & HR strategies & Strategic reference points \\
\hline Advantage & Less cost & As a result & Focus on process & Control \\
Focus & More focus & As a result & Supply from inside & Supply \\
\hline
\end{tabular}


In the case of business strategy, if the basis for the competitive advantage is different cost and competitive area, we should focus on the results and costs of doing things, as well as the resources available to the organization. In this way, the choice of human resources strategies should be based on this.

\section{Distinction - Focus strategy}

When an organization tries to provide distinct and diverse services to specific and limited audiences, it must use Distinction - Focus strategy that requires high costs and supplying human resources from outside the organization. Also, the organization has no problems in providing resources and the focus on the process is due to the simple and repetitive nature of the jobs. In this case, the competitive advantage is high cost, but the focus area is high focus and limited service provision, therefore, the organization must act on providing resources from outside the organization in order to provide appropriate services, but because of the simplicity and repeatability of the services, it can monitor the whole process. So the focus is on the process.

\section{Table 10}

Basis of alignment in strategies based on distinction and focus

\begin{tabular}{ccccc}
\hline Strategic reference points & Business strategy & & HR strategies & Strategic reference points \\
\hline Advantage & High distinction & As a result & Focus on process & Control \\
Focus & More focus & As a result & Supply from outside & Supply \\
\hline
\end{tabular}

In the case of business strategy, if the basis for the competitive advantage is the high distinction and limited competitive area, occupations have priority that have less complexity but no need to supply from inside. Thus, we should focus on HR strategies that are process-oriented and supplying resources should be from outside the organization.

\section{Distinction - Separation strategy}

When the university tries to provide distinct and diverse services to different audiences, it needs to use a Distinction - Separation strategy that requires high cost and distinction and supplying human resources from outside the organization. Because the organization is not able to attract all human resources to provide diverse services and is required to supply from outside of the organization. Focusing on the outcome is also due to high due to the variety of services and high complexity and expertise. In this case, the separation activity area is high and the provision of services is different, therefore, the organization must act on providing resources from outside the organization in order to provide its diverse services but due to the complexity of the services, it cannot monitor the entire process. So the focus is on the outcome.

\section{Table 10}

Basis of alignment in strategies based on distinction and separation

\begin{tabular}{ccccc}
\hline Strategic reference points & Business strategy & & HR strategies & Strategic reference points \\
\hline Advantage & High distinction & As a result & Focus on outcome & Control \\
Focus & More separation & As a result & Supply from outside & Supply \\
\hline
\end{tabular}

In the case of business strategy, if the basis of competitive advantage is high distinction and a diverse competitive area, then jobs have priority that have a high complexity and need to provide from outside the organization.

\subsubsection{Fuzzy rules explanation}

According to the studies, 16 fuzzy rules were defined for business strategies and 4 human resources strategies were defined in the software. By using these rules it will be clear which of the HR strategies 
are aligned with business strategies. In this example (Fig. 3), it is clear that the rules are explained as follows, three of which are listed for example, and the rest are also specified in the software:

1. The process control, inside supply is completely unaligned with a competitive advantage of low cost and focused area.

2. Process control, inside supply is relatively unaligned with a competitive advantage of low cost and a separated area.

3. Process control, inside supply is unaligned with a competitive advantage of high distinction and focused area.

\begin{tabular}{|c|c|c|c|c|c|c|c|c|c|c|}
\hline & & Name & e IIIII If & And & Operators & Then & With & And & With & Comment \\
\hline$\theta$ & B1 & RB1 & 1 & 2 & Min / Max & $x 1$ & & 2 & & \\
\hline$\theta$ & B1.G1 & & Control & Supply & & III] Advantage & Dos [\%] & It Focus & $\operatorname{Dos}[\%]$ & \\
\hline$\theta$ & B1.G1.R1 & & $\perp \Lambda$ Control_Process & $s \mid \Lambda$ Supply_Inside & $\Rightarrow$ & $\lfloor$ Advantage-Low & 100 & $0\lfloor$ Focus_High & & CA \\
\hline$\theta$ & B1.G1.R2 & & $\perp$ Control_Process & $5 \mid \Lambda$ Supply_Inside & $\Rightarrow$ & $\Perp$ Advantage.Low & 25 & $5\lfloor$ Focus_Low & & RUA \\
\hline$\theta$ & B1.G1.R3 & & $\perp \Lambda$ Control_Process & $s\lfloor$ Supply_Inside & $\Rightarrow$ & $\Perp$ Advantage.High & & $0\lfloor$ Focus_High & & 5 UA \\
\hline$\theta$ & B1.G1.R4 & & $\perp \Lambda$ Control_Process & $s \mid \Lambda$ Supply_Inside & $\Rightarrow$ & $\amalg$ Advantage.High & & $0\lfloor$ Focus_Low & & CUA \\
\hline$\theta$ & B1.G1.R5 & & $\perp \Lambda$ Control_Process & s $\lfloor\Lambda$ Supply-Outside & $\Rightarrow$ & \ Advantage.Low & & $0\lfloor$ Focus_High & & 5 UA \\
\hline$\theta$ & B1.G1.R6 & & $\perp \Lambda$ Control_Process & ${ }_{5}\lfloor\Lambda$ Supply-Outside & $\Rightarrow$ & \Advantage-Low & & $0\lfloor$ Focus_Low & & CUA \\
\hline$\theta$ & B1.G1.R7 & & $\perp \Lambda$ Control_Process & $5\lfloor\Lambda$ Supply-Outside & $\Rightarrow$ & $\amalg$ Advantage.High & 100 & $0\lfloor$ Focus_High & & CA \\
\hline$\theta$ & B1.G1.R8 & & $\perp \Lambda$ Control_Process & $s\lfloor\Lambda$ Supply-Outside & $\Rightarrow$ & $\downarrow$ Advantage.High & 25 & $5\lfloor$ Focus_Low & & RUA \\
\hline$\theta$ & B1.G1.R9 & & $\perp \Lambda$ Control_Result & $\lfloor$ Supply_Inside & $\Rightarrow$ & $\amalg$ Advantage_Low & 25 & $5\lfloor$ Focus_High & & RUA \\
\hline$\theta$ & B1.G1.R10 & & $\perp \Lambda$ Control_Result & $\lfloor$ Supply_Inside & $\Rightarrow$ & 【 Advantage.Low & 100 & $0\lfloor$ Focus_Low & & CA \\
\hline$\theta$ & B1.G1.R11 & & $\perp \Lambda$ Control_Result & $\lfloor$ Supply_Inside & $\Rightarrow$ & $\amalg$ Advantage.High & & $0\lfloor$ Focus_High & & CUA \\
\hline$\theta$ & B1.G1.R12 & & $\lfloor\Lambda$ Control_Result & $\lfloor$ Supply_Inside & $\Rightarrow$ & $\amalg$ Advantage.High & & $0\lfloor$ Focus Llow & & 5 UA \\
\hline$\theta$ & B1.G1.R13 & & $\lfloor\Lambda$ Control_Result & $\lfloor$ Supply.Outside & $\Rightarrow$ & \Advantage.Low & & $0\lfloor$ Focus_High & & CUA \\
\hline 0 & B1.G1.R14 & & $\Lambda$ Control_Result & $\Lambda$ Supply.Outside & $\Rightarrow$ & IL Advantage.Low & & $0\lfloor$ Focus_low & & 5 UA \\
\hline$\theta$ & B1.G1.R15 & & $\lfloor\Lambda$ Control_Result & $\lfloor\Lambda$ Supply_Outside & $\Rightarrow$ & $\Perp$ Advantage.High & 25 & $5\lfloor$. Focus_High & & RUA \\
\hline$\theta$ & B1.G1.R16 & & $\perp \Lambda$ Control_Result & $\perp \Lambda$ Supply_Outside & $\Rightarrow$ & $\Perp$ Advantage.High & 100 & $0\lfloor$ Focus_low & & CA \\
\hline
\end{tabular}

Fig. 3. Rules defined in software based on fuzzy logic

Based on the performed design, it is determined that the reference points of control and supply of resources are conversely correlated with each other and this relation was developed in the software as follows:

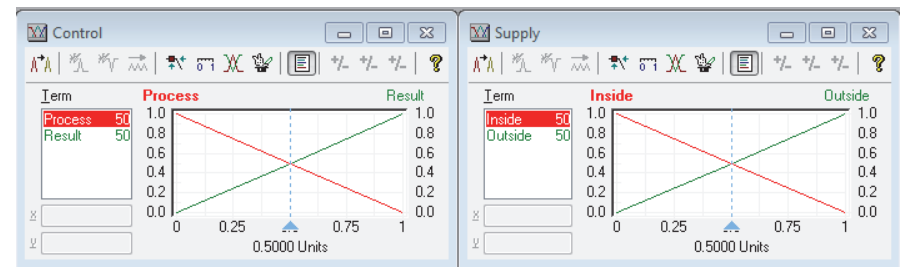

Fig. 4. Explaining the relation between Control and Supply in Human Resources Strategy

According to the defined rules, it is clear that more control at the university which goes to the process and focus on providing resources is within the organization and is aligned with the business strategy that its focus is on lower costs and a more competitive area. This inference is also indicated in Fig. 5.

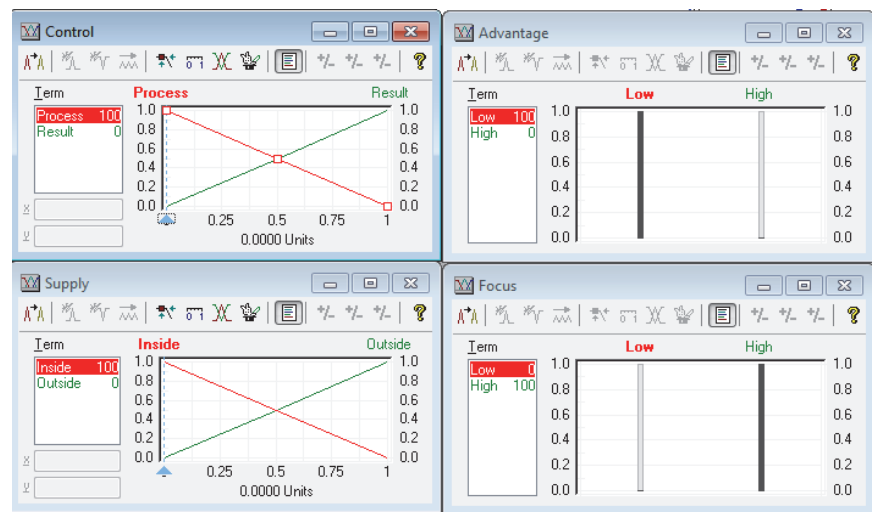

Fig. 5. Studying the results of strategies alignment in process control and inside supply 
Based Fig. 5., it is clear that if the control on the left of the model is towards the process and the supply is also from inside the organization, the alignment of business strategies goes toward lower cost advantage and area with high focus.

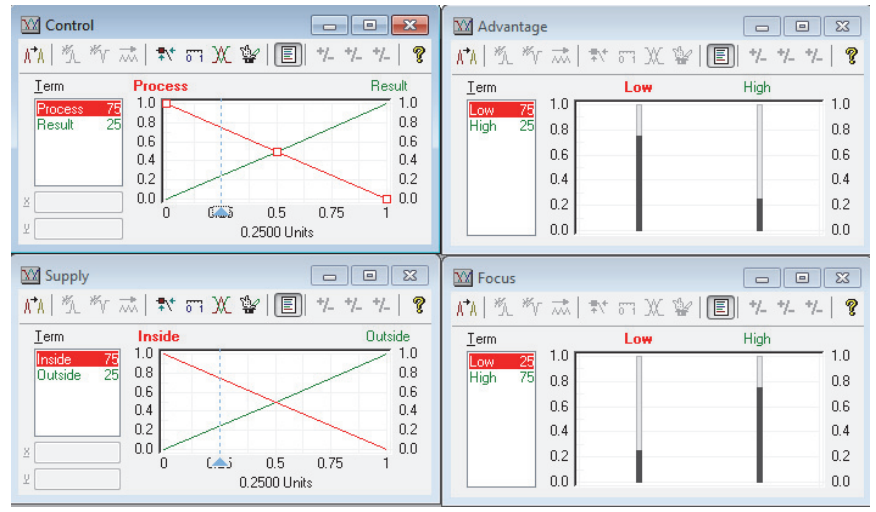

Fig. 6. Reviewing the results of alignment strategies in the relative control of the process and the inside relative supply

It is shown in Fig. 6 that if process control is not complete and part of the control is due to result, and when the full supply is not from inside resources and some of the resources are supplied from outside, alignment with business strategies will be changed and at the same rate of 0.25 , a combination of cost competitive advantage, distinction, focus and separation strategies are required.

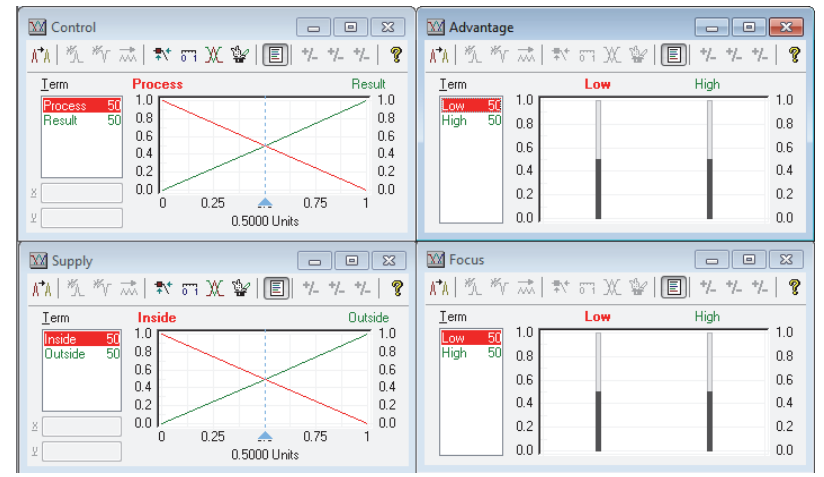

Fig. 7. Studying the results of strategies alignment in the average controlling of process and average supplying from the inside

It is shown in Fig. 7 that when the process control is average, that is, at $50 \%$, it means that half of the result control is based on the process and half of the control is over the results, and if the same thing happens to supply resources, business strategies are also quite relative, and there is no particular alignment because the obtained results are 50 percent for the four business strategies.

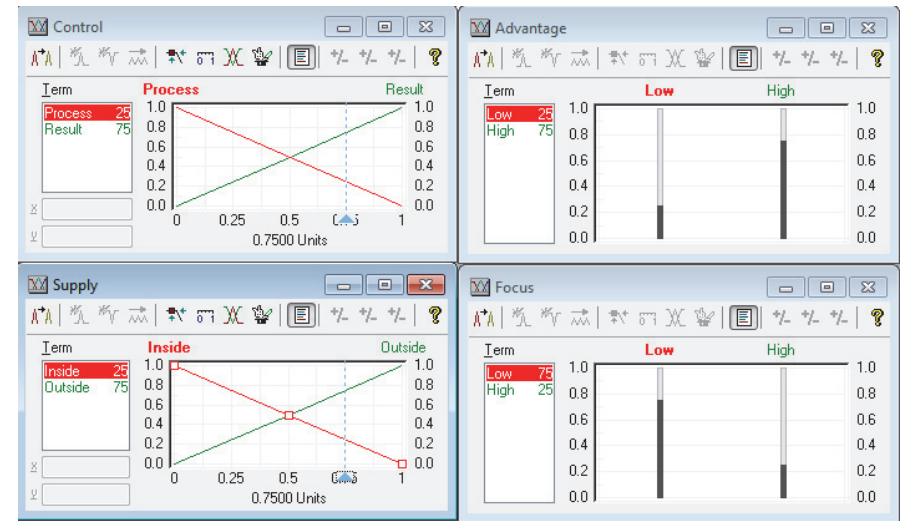

Fig. 8. Studying the results of the alignment of strategies in controlling the relative supply from outside 
In Fig. 8, it is shown that if the control of the result is not complete and part of the control is also due to the process and also, when the full supply is not provided from the outside resources and part of the resources are provided from the inside, the alignment with business strategies also will be changed to some extent and at the same rate of 0.25 , a combination of competitive advantage of distinction and cost as well as a separation and focus strategies are required.

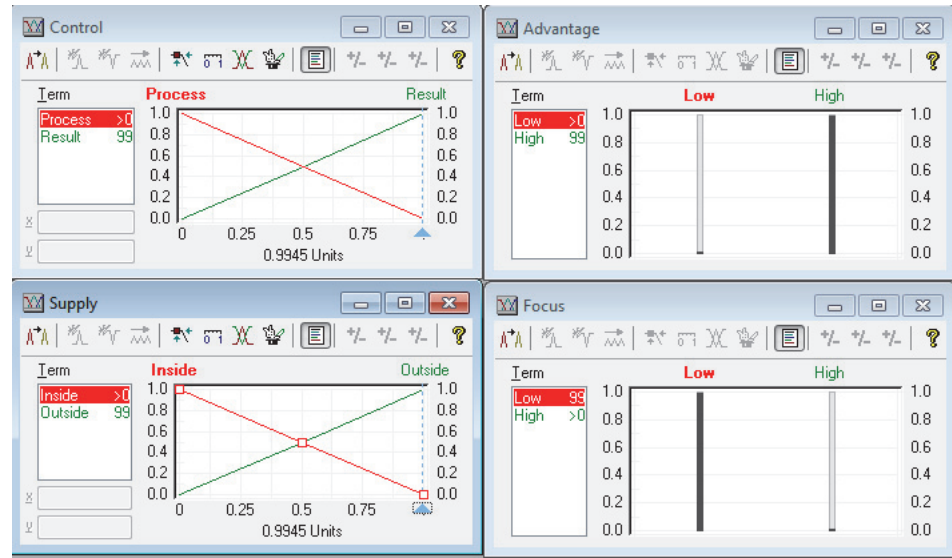

Fig. 9. Studying the results of strategies alignment in controlling outcome and supply from outside

Based on Fig. 9, it is clear that if the control at the right of the model is towards the result and supply is also towards the outside of the organization, the alignment of business strategies goes toward the advantage of higher distinction (higher cost) and the area with a more separation (lower focus). In this way, the main modes of the model were displayed in 5 sections. According to the calculated rules, the experts' questionnaire data was entered into the software and based on the results, it was clear how the alignment of strategies was explained in terms of academic experts. The results are presented in Table 12.

Table 12

The result of strategy alignment based on the output of the software

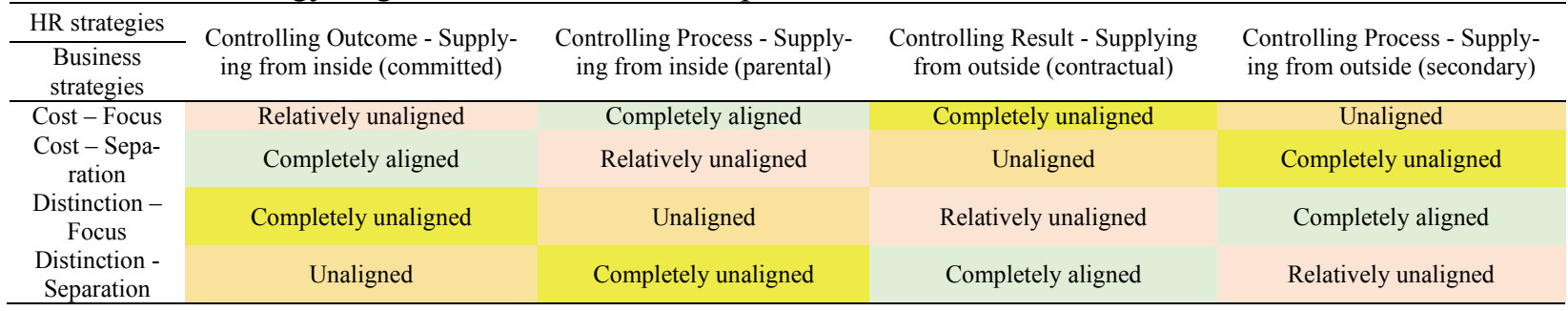

\section{Discussion and conclusion}

In this research, we have presented a fuzzy framework for aligning human resource strategies with business strategies at University of Applied Science and Technology. For this purpose, first, strategic reference points were identified and extracted from the previous studies. Then these points were confirmed by the experts. Fuzzy Delphi technique was used to validate the reference points. The results showed which of the strategic reference points were suitable for the university. Then fuzzy logic was used to determine the alignment of the strategic reference points corresponding business and human resources. For this purpose, the logic of alignment was first discovered using the experts' opinions and the study of articles and literature and then the then - if rules were explained in Fuzzytech software. Finally, using the analysis, it was determined which business strategies were aligned with human resources strategies. Subsequently, suggestions were presented based on 16 possible states between business strategies and HR strategies. In this section, each state was explained first and based on the desirability of each mode, a suggestion was presented. 


\section{Table 13}

\section{Possible states and Proposed Strategies}

\begin{tabular}{l} 
Cost-focus \\
\hline In this situation, the university has chosen cost and focus strategy in its business development, and it is expected to provide certain low-cost services to a \\
specific section chosen by managers. Due to the need to reduce costs as much as possible, the university must control the processes in order to reduce the \\
cost of each activity. Controlling the result cannot be desirable for the university, since controlling the result makes it impossible to modify the process \\
and reduce the cost for the university. But the supply of resources from the inside is desirable due to the recruitment of the required force for a particular \\
part of the activities. Therefore, it is suggested that in case of such a situation, the university tries to change the control of the outcome of the process. \\
University executives can achieve the expected outcomes by explaining new policies for monitoring and evaluating and designing process-oriented control \\
operational programs. \\
\hline Cost-separation
\end{tabular}

When the university, plans to cut the costs of its activities and also decide to provide services to different audiences, it is forced to use resources in a variety of projects and, as much as possible, fill in the hours of work of its employees. In this case, there is no way to control the process of all projects and activities and university administrators should focus on the expected outcomes by increasing their employees' authority so that they can provide the required services in all sectors with good quality. In such a situation, adopting a committed strategy is desirable for managers. Therefore, it is suggested that if the business strategy of the university proceeds to cost and separation strategy in the future, human resources strategy will direct itself towards a committed strategy in order to achieve the best expected result.

Distinction-Focus Controlling Outcome - Supplying from inside (committed) Completely unaligned

The focus and distinction strategy requires focusing on the centralized section of the market and avoiding and providing a variety of services. But for such a centralized service, the university tries to provide the best and most high-quality services that require a high cost. When university is in such a situation, it is needed to provide human resources from outside and control processes, but a committed strategy is totally contrary to the university's desirable strategy and managers should quickly modify their human resources strategy. Therefore, managers are encouraged first to focus on providing resources from outside and benefit the best people in order to increase their quality of service. Also, if individuals available to the university are reliable forces and famous professors, the university can also benefit from a mix of supplying both inside and outside. It is also suggested that university managers try to change the assessment of the final results and focus on the implementation of process.

Distinction-separation Controlling Outcome - Supplying from inside (committed)
Unaligned

When the university seeks to increase the distinction and separation of its business area, it must focus on the outcome of defined activities and projects which in this regard part of the human resource strategy is considered desirable in this situation but, it is almost impossible to provide all the required resources from inside, due to the high level of expertise, as it imposes a great cost on the university. In this situation, it is suggested that the university prioritizes its activities and provide activities that are part of the competitive advantage of the university, by supplying inside resources and recruiting employees and specialists to carry out other activities from outside the university.
Cost-focus
Controlling Process - Supplying from inside (parental)
Completely aligned

Reducing costs and focus on specific goals requires process control and supply from the inside. In this case, the human resources strategy is completely align with the business strategy. If such a situation happens for the university and the university intends to focus on a specific group of audiences and reducing costs as much as possible, the strategy of controlling the process and providing resources through the recruitment of the required people is the best.

Cost-separation Controlling Process - Supplying from inside (parental)

Relatively unaligned

Cost and separation strategy requires cost control as much as possible and creating variety of services. This diversity in services should be created in the light of the maximum use of available resources and there is no possibility for a university to use contractual employees because the expertise needed to provide a variety of services is highly cost and there is no possibility for the university to spend more. Hence, if the university chose a cost - distinction strategy for its business and if the business strategy was paternal, managers should keep in mind that controlling the process of all activities for managers may close the hand of the internal forces and prevent them from providing all the required services. Therefore, it is better to change the human resources strategy to the committed or the managers of the university try to reduce the control of processes and gradually change control of the process to the result. Distinction-focus Controlling Process - Supplying from inside (parental) Unaligned

In this situation, the human resources strategy is not align with the business strategy and non-alignment clears a change in strategy. For a university, changing business strategy is not possible due to the cost conditions and inspecting available resources, and the best way is to change and refine the human resources strategy. In this situation, for a university that has chosen a Distinction-focus, it is not possible to provide resources from outside due to the high quality of services and the university prefers to employ the best man power from other universities and academic centers for its limited services. Therefore, it should try to create the possible distinction by identifying the best professors and man power in the field of required services. If the university can recruit these people instead of the current forces, it can do so.

Distinction-separation Controlling Process - Supplying from inside (parental) Completely unaligned

The current status of the university is currently this item, that according to the survey, three scenarios were proposed to change it. The Distinctionseparation strategy requires a high level of expertise that makes it difficult for the university administrators to take full control of the process and because of the high cost of providing these professionals, it is not possible to recruit all of them, and the university is forced to provide resources from outside the university. So we can see why these two strategies are completely unaligned. In order to create alignment, the strategy of supplying resources must proceed towards supply from outside and control the outcome. Cost-focus Controlling Result - Supplying from outside (contractual) Completely unaligned

When the university wants to provide services to a particular group of audiences, must concentrate the range of controlling the activities on the process so that it can reduce the cost of doing the activities. It also needs to recruit a minimum forces for providing limited services and supplying them from inside the university is very desirable and optimal and it can greatly reduce university costs. Choosing a contractual human resource strategy is completely unaligned and incompatible with the business goals of the university. Because contractual strategy puts control of the outcome at the top of its planning and it is needed to provide resources and expertise from outside the university, that both of which are contrary to the business purpose of the university. Therefore, it is suggested to managers that in case of such a situation, they will change their HR strategy to paternal or try to prioritize activities and make the control some activities in the shape of process oriented and focus on providing these core activities from inside the organization. Cost-separation Controlling Result - Supplying from outside (contractual) Unaligned

When the university wants to use cost-separation strategy for its business, it must try to provide resources from the inside because there is no possibility for the university to spend, and the university wants to expand its field of work, taking into account the minimum cost. Therefore, it is necessary to use the force at its disposal as much as possible, and it is not possible to recruit forces from outside the university due to the high cost of specialist contractual forces. Therefore; contractual strategy is not align with the business strategy of cost and separation, and the university must try to change its human resources strategy. The university can also allocate services to the extent possible on the basis of the capabilities of its specialists and, if needed, recruit foreign forces, in which case it has use a mix of committed and contractual strategies. 
Table 13

Studying possible states and Proposed Strategies (Continued)

Distinction-focus Controlling Result - Supplying from outside (contractual)

Relatively unaligned

The business strategy of Distinction-focus has a high demand for supplying the required power from outside the university because the university plans to provide its services with the highest quality, and it is not possible to attract and employ all the qualified forces for the university. Hence, supplying resources from outside has the priority in making decisions. Also, in contractual strategy, the focus of monitoring is on the outcome, that according to the limited scope of activities, there is the possibility of controlling the process for managers. For this reason, if such a situation occurs, it is suggested that managers improve the supervision and control in their planning and by shifting control from the outcome to the process, make the HR strategy aligned with the business strategy.

distinction-separation Controlling Result - Supplying from outside (contractual) Completely aligned

When the university plans to act in a pivotal manner in different areas and provide distinct services, It is required to use a variety of specialties that, due to the high cost of specialists, it is not possible to recruit all of them. For this reason, supplying from outside and project and part-time recruitment of specialists are more profitable for the university. It means that the university can recruit for its main competitive advantages and then use the contractual forces to make distinction and separation. Thus, university costs are greatly reduced. Also, due to the high expertise of each specialist and the diversity of projects and services due to the separation in the chosen field, the model of monitoring on process cannot be used. Because this monitoring requires a very high and long-term expertise, and it's practically impossible due to the cost pressures of rivals. Rather, the university should examine the expected accomplishments based on the results obtained and inspection outcomes of each project. By doing so, these two strategies are perfectly aligned with each other, and taking advantage of it will put the university in the best position.
Cost-focus
Controlling Process - Supplying from outside (secondary)
Unaligned

Business strategy based on cost and focus requires cost savings as much as possible, and process control of activities can provide managers with this opportunity. But supplying man power from outside of university is not a desirable item for cost-focus strategy Because supplying man power from outside of university requires cost increase and it is not cost-effective for the university to recruit in a variety of specialized staff as contractual for a limited number of activities. Therefore, it is suggested that in case of such a situation, the university will seek to recruit its man power. Thus, changes its human resources strategy from the secondary to the paternal

Cost-separation

Controlling Process - Supplying from outside (secondary)

Completely unaligned

The adoption of a secondary human resources strategy is completely unaligned with the business strategy of cost and separation. Because both process control and supply from the outside have priority in the secondary strategy. That is, control point as well as a supply method are both totally disproportionate. In this case, the human resources strategy must change into a committed strategy. If the university is in this situation, first it is better to stop recruiting resources from outside and try to plan the separation of services based on its own internal forces. Then through focus on inside resources reduce costs as much as possible. Then plan for increasing the strength of its forces and increase the scope of service based on the capabilities. It can also gradually leads the process control to controlling the result.

Distinction-focus Controlling Process - Supplying from outside (secondary) Completely aligned

The distinction-focus strategy focuses on providing high-quality services but for a limited group of audiences. In this case, considering that the University plans to provide the best quality of education and academic services, it tries to recruit the best professors from various universities, but does not recruit them permanently. Also, given that the number of these specialists is low due to the focus on a certain area of services, the university can monitor the process of providing services. Therefore, the adoption of a secondary strategy in this situation is very desirable. If the university is in this situation, there is a perfect alignment between strategies and it is suggested that managers continue their activities.

Distinction-separation Controlling Process - Supplying from outside (secondary) Relatively unaligned

Creating a distinction in services and separating the service area requires a very high level of expertise and the strategy of supplying these resources from outside the organization is highly aligned with the business strategy. But process control is not possible due to the variety of activities. In this case, it is suggested to university administrators to identify the core activities of the university and focus on controlling the process of these activities, and control other activities that are sub-categorized or lower-ranked, based on expected results. Because it seems that in this case, the process of all activities cannot be controlled and separation of these activities is the most effective way for administrators to control the process mixed with outcome.

\section{References}

Abbasi, A., Mosleh Shirazi, A., Hosseini, F. (2017). Developing Human Resource Strategy Coherent with Business Strategies, Culture and Organizational Structure. Journal of Research in Human Resources Management, 9(2), 21-46.

Ahmadi, A., Amin, F., \& Kateb, M. (2017). Alignment of business strategy and human recourse strategy with SRP model in UAST. Public Organizations Research, 5(3), 130-113.

Amin, F. (2015). Appraisal of the Effects of Strategic Trade Parallelism and Human Resource on Financial Key Performance and Employees' Satisfaction. Journal of Research in Human Resources Management, 7(2), 105-127.

Arabi, S.M., \& Moghaddam, A. (2007). Strategic Alignment between Human Resource Strategy, Business Strategy, and Corporate Culture. Iranian Journal of Management Sciences, 2(8), 103-135.

Azar, a., Khosravani, f., Jalali, r., \& Dehdashti, a. (2011). University life cycle-fuzzy approach. Journal of Research and Planning in Higher Education, 16(159), 1-25.

Batarlienė, N., Čižiūnienè, K., Vaičiūtè, K., Šapalaite, I., \& Jarašūnienė, A. (2017). The impact of human resource management on the competitiveness of transport companies. Procedia Engineering, 187, $110-116$

Bird, A., \& Beechler, S. (1995). Links between business strategy and human resource management strategy in US-based Japanese subsidiaries: An empirical investigation. Journal of International Business Studies, 26(1), 23-46. 
Divandari, A., Nazari, M., Razavi, S.M. \& Amin, F. (2014). Identify and ranking the affecting factors on align business strategy and human resource management practices with Blue Ocean approach and electric technique. Industrial Organization Journal, 6(2), 283-302.

Feigenbaum, A. V. (1999). The new quality for the twenty-first century. The TQM magazine, 11(6), 376383.

Gannon, J. M., Roper, A., \& Doherty, L. (2015). Strategic human resource management: Insights from the international hotel industry. International Journal of Hospitality Management, 47, 65-75.

Heneman III, H. G., \& Milanowski, A. T. (2004). Alignment of human resource practices and teacher performance competency. Peabody Journal of Education, 79(4), 108-125.

Holbeche, L. (2009). Aligning human resources and business strategy. Routledge.

Karyotis, C., Doctor, F., Iqbal, R., James, A., \& Chang, V. (2018). A fuzzy computational model of emotion for cloud based sentiment analysis. Information Sciences, 433, 448-463.

Linton, G., \& Kask, J. (2017). Configurations of entrepreneurial orientation and competitive strategy for high performance. Journal of Business Research, 70, 168-176.

Mahmoud Janlou, R. (2017). Strategy of Human Resources using the Theory of Strategic Reference Points (Case Study of Amirabad Port Special Economic Zone). Journal of Maritime Transport Industry, 3(1), 36-44.

Ou, C. W., Chou, S. Y., \& Chang, Y. H. (2009). Using a strategy-aligned fuzzy competitive analysis approach for market segment evaluation and selection. Expert Systems with Applications, 36(1), 527541.

Saini, D. S. (2003). Aligning human resources and business strategy. Indian Journal of Industrial Relations, 38(3), 374-380.

Siahkali Moradi, J., Khosravani, F., \& Ayazi, S.A. (2017). A model of effective factors on pubic organizational corruption in street level bureaucrats with using a hybrid approach of Delphi and ISM, the first international conference and the third national conference on management and humanities research, University of Tehran.

Ulrich, D., Brockbank, W., Yeung, A. K., \& Lake, D. G. (1995). Human resource competencies: An empirical assessment. Human Resource Management, 34(4), 473-495.

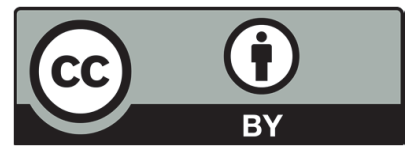

(C) 2018 by the authors; licensee Growing Science, Canada. This is an open access article distributed under the terms and conditions of the Creative Commons Attribution (CCBY) license (http://creativecommons.org/licenses/by/4.0/). 